\title{
Fällung der alten Leas Eiche (Quercus x leana) im Palmengarten
}

\author{
Hilke Steinecke
}

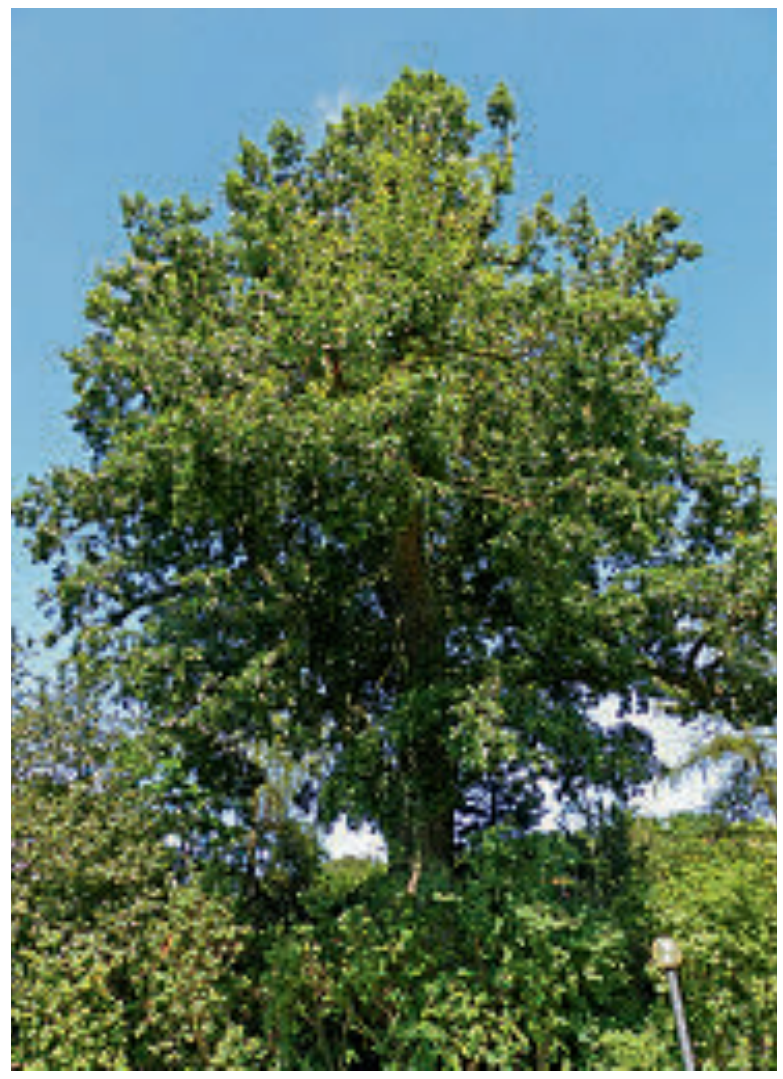

Leas Eiche ist eine Naturhybride zwischen den beiden nordamerikanischen Arten Quercus imbricaria (Schindel-Eiche) und Q. velutina (Färber-Eiche). Entdeckt wurde sie um 1830 in der Nähe von Cincinnati/Ohio von dem Botaniker Thomas Gibson Lea, nach dem sie auch benannt wurde.

Diese Eiche ist schnellwüchsig, wird 20-30 m hoch und entwickelt dabei eine breite Krone. Die Blätter ähneln denjenigen der Schindel-Eiche. Sie haben also nicht die typische Eichenblattform. Sie sind ungelappt, seicht oder tief gelappt und insgesamt sehr variabel in ihrer Form. Die eiförmigen, etwa $2 \mathrm{~cm}$ langen Eicheln werden etwa bis zur Hälfte vom Eichelbecher (Cupula) umgeben. Sie ähneln den Früchten der Färber-Eiche. Wie bei vielen Hybriden sind die Samen auch von Leas Eiche steril.

Unsere Leas Eiche war einer unserer ältesten und größten Bäume im Palmengarten. Sie war älter als der Palmengarten selbst und wurde vermutlich in der Mitte des 19. Jahrhunderts gepflanzt. Der Baum hatte zuletzt einen Umfang von 6,69 m, eine Höhe von ca. $27 \mathrm{~m}$ und einen Kronendurchmesser von ca. $17 \mathrm{~m}$.

An dem Baum wurden in den vergangenen Jahrzehnten bereits umfangreiche Sanierungsmaßnahmen wie Kronenrückschnitte, Kronensicherungen und Sanierungen und Verschluss der offenen Höhlung am Stammfuß durchgeführt. Zwei Schadpilze (Schwefelporling und Eichenfeuerschwamm) wurden vom Baumsachverständigen beobachtet. Im Nachhinein konnte nach der Fällung an Stammquerschnitten festgestellt werden, dass das Pilzmyzel in einem großen Teil des Baumes bereits nicht nur wie üblich das Splintholz befallen hatte, sondern auch in das auffällig rote Kernholz eingedrungen war. An vielen Stellen war Braunfäule zu erkennen.

Der Baum wurde vor der Fällung auf Bruchund Standsicherheit untersucht. Eine Standsicherheit, besonders auch bei Sturm und Schneelast, konnte nicht mehr garantiert werden, zumal der Baum in den unteren $4 \mathrm{~m}$ bereits ziemlich hohl und morsch war. Der Baum befand sich in einem Bereich, der von vielen Besuchern frequentiert wird (Minigolf, Palmenexpress-Haltestelle, Spielwiese, Wasserspielplatz), sodass das Risiko zu groß war, ihn hier stehen zu lassen.

Leas Eiche wurde am 14. Dezember 2016 gefällt. Zufälligerweise stimmte der Fälltermin mit dem Geburtstag von T. G. LEA, geboren am 14. Dezember 1785, überein. Die eigentliche Fällung dauerte einen ganzen Arbeitstag, die Beseitigung der großen Holzreste einen zweiten. Insgesamt war der Baum etwa 50-60 Tonnen schwer. Einen Teil des Holzes werden Drechsler verarbeiten. Auch der Palmengarten hat als Erinnerungsstücke an diesen prominenten Baum einige große Holzscheiben behalten. 

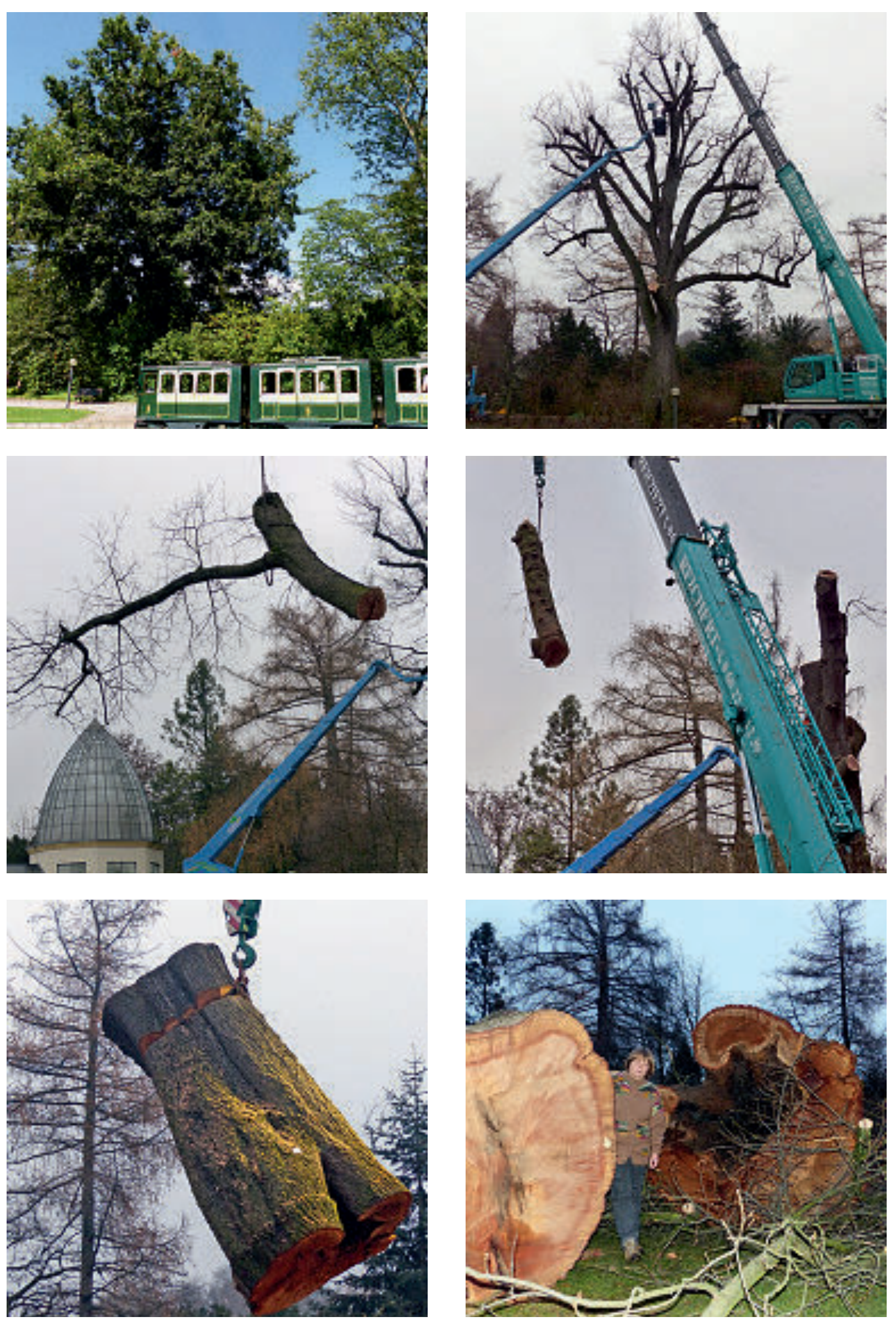